\title{
Estudos brasileiros de literaturas africanas - implicações neocoloniais e contradições raciais
}

\author{
Brazilian studies of African literatures - neocolonial \\ implications and racial contradictions
}

Ricardo luiz Pedrosa Alves ida

\section{Resumo}

O artigo discute aspectos contraditórios dos estudos brasileiros de pós-graduação sobre literaturas africanas. São abordadas as implicações neocoloniais e os paradoxos raciais presentes no conjunto de dissertações e teses brasileiras sobre literaturas africanas. Destacamos o caso dos estudos sobre o escritor moçambicano Mia Couto como característicos de tais contradições.

Palavras-chave: Literaturas africanas. Questão racial. Neocolonialismo. Mia Couto.

\begin{abstract}
The present article discusses contradictory aspects of the Brazilian postgraduate studies on African literatures. Neocolonial implications and racial paradoxes present in Brazilian dissertations and theses on African literature are addressed. The article highlights the case of studies on the Mozambican writer Mia Couto as characteristic of such contradictions.
\end{abstract}

Keywords: African literatures. Racial issues. Neocolonialism. Mia Couto.

\footnotetext{
a Universidade Estadual de Ponta Grosa (UEPG), Ponta Grossa, Paraná, Brasil. Doutor em Letras, e-mail: ricardopedralves@gmail.com
} 


\section{Introdução}

Este artigo parte de questões bastante diretas, mas cujas respostas nos parecem imensamente complexas. Serão as leituras brasileiras de literaturas africanas indiferentes às questões raciais, manifestando a seu modo o racismo histórico, institucional, sistêmico e estrutural brasileiro? Como pensar o direito da população afrodescendente brasileira de interagir com as literaturas africanas do passado e do presente? Que relações podem ser pensadas entre as leituras brasileiras de literaturas africanas e a luta antirracista no Brasil? Em que medida as restrições neocoloniais como um mercado editorial global que massifica a presença de poucos autores, ou como a herança lusófona que paira sobre as relações entre o Brasil e o Continente Africano - estão implicadas nessa discussão? Num recorte determinante no horizonte de expectativas brasileiras quanto à literatura africana, deve-se perguntar o porquê de o autor moçambicano Mia Couto estar presente em mais de 25\% das pesquisas sobre literaturas africanas. Por fim, qual o modo de comprometimento das pesquisas de literaturas africanas nas universidades brasileiras com as lutas antirracistas? A discussão de um artigo não dá conta de questões assim tão complexas e de implicações interseccionais. As possibilidades deste texto são apenas as de subsidiar futuras reflexões e práticas de pesquisa. O que pretendemos aqui, nesse escopo investigativo e inquisitivo, é abordar tais demandas a partir de um campo bem delimitado, o das dissertações e teses brasileiras sobre literaturas africanas, defendidas na Pós-Graduação da área de Letras. De outro lado, um tema tão múltiplo e problemático não merece ser abordado fora de certa porosidade interdisciplinar, ou mesmo discursiva. Assim, preferimos uma exposição um tanto fragmentada, de modo a provocar fricções entre os diferentes momentos da reflexão. No passado da vida acadêmica brasileira, antes da instituição do dito Homo lattes, tal gênero textual mereceria o nome de ensaio. Como ensinou também outra voz do passado, a adequada exposição dos movimentos do real se obtém na articulação diferenciada do método de investigação em relação ao método de exposição (MARX, 1985).

A relação cultural transnacional que decorre da recepção de literaturas africanas no Brasil será aqui analisada a partir de um conjunto de pesquisas na Pós- 
Graduação brasileira. O material foi levantado, na sua maior parte, junto ao Catálogo de Teses e Dissertações, disponibilizado através de um site pela Coordenação de Aperfeiçoamento de Pessoal de Nível Superior (CAPES). O panorama obtido, a partir das 1000 pesquisas defendidas entre 1979 e 2018, permite delinear as linhas de força que orientaram a formação do campo de estudos. Além de traçar um histórico da área, oferecendo um instantâneo do campo, a pesquisa trata das correntes de interesse, das categorias teóricas e das metodologias utilizadas nas investigações. O panorama permite pensar questões como o lugar das literaturas africanas no sistema literário brasileiro e, para o que nos interessa particularmente neste texto, as complexas relações entre dimensões como a lusofonia, as relações raciais e os perigos da neocolonialidade. Destacaremos o caso da recepção brasileira ao escritor moçambicano Mia Couto como sendo central às discussões deste artigo. Quanto à lusofonia, trataremos da ênfase que se dá, nas dissertações e teses brasileiras, à África de expressão literária portuguesa, o que indica um recorte parcial das literaturas do continente, igualmente insatisfatório para o futuro das chamadas literaturas africanas comparadas (BRUGIONI, 2019). No tocante às relações raciais, discutiremos aspectos ainda problemáticos da relação entre a política afirmativa sistematizada na Lei 10639 (BRASIL, 2003) e o crescimento das literaturas africanas no Brasil, destacando heranças estruturais neocoloniais, expressas na branquitude dos nomes africanos mais estudados na Pós-Graduação brasileira, como é o caso de Mia Couto, mas não somente dele. Outro dos aspectos centrais da neocolonialidade diz respeito ao que chamamos de sequestro de interesses da pesquisa acadêmica pelo mercado editorial, importante em se tratando de literaturas africanas, usualmente de baixa presença editorial.

Após esta introdução, o artigo iniciará por um breve histórico das relações transnacionais entre o Brasil e o Continente Africano. A pesquisa literária em tela não pode ser discutida fora de tal escopo histórico. Optamos, inclusive, por uma aproximação a tais aspectos históricos através do delineamento de duas trajetórias intelectuais que, talvez, expressem com maior nitidez os aspectos de colonialidade herdados pela pesquisa atual de literaturas africanas. Falamos dos escritores Tomás Antônio Gonzaga e Castro Soromenho, nomes que mostram a complexa evolução histórica das dinâmicas intelectuais entre o Brasil e o Continente Africano. Na 
sequência, o artigo voltará aos temas já elencados na abertura, com a apresentação do panorama de dissertações e teses e com as discussões decorrentes, destacando o caso da recepção da literatura de Mia Couto no Brasil.

\section{Um "brasileiro" e um "angolano"}

A introdução de aspas na qualificação nacional de Tomás Antônio Gonzaga e de Castro Soromenho objetiva mostrar que sua condição de intelectuais das colônias de Portugal precisa sempre de ser relativizada no quadro das relações coloniais que se estabeleceram desde o século XVI. Nesse quadro, durante séculos houve dois tipos de trânsitos transnacionais entre Portugal, Brasil e territórios africanos. De um lado, o genocídio da escravização das populações negras africanas, na diáspora involuntária e desumanizante da história da escravidão brasileira. De outro, um trânsito das elites brancas coloniais e portuguesas pelos territórios, seja nos estamentos administrativos, seja nos negócios coloniais de expropriação, tráfico e escravização. As atividades literárias sempre estiveram monopolizadas por essas elites brancas, que transitaram por três continentes e estabeleceram redes de solidariedade elitizadas. Se é possível falarmos, com Abdala Junior, de "discursividades supranacionais" (ABDALA JUNIOR, 2008) ou de, com base na solidariedade das condições históricas, em uma "comunidade cultural ibero-afro-americana" (ABDALA JUNIOR, 1996), pois sempre houve (e há) intercâmbios culturais e experiências históricas compartilhadas, também é necessário ressaltar que a estrutura colonial teve sua matriz em Portugal, operada nas colônias por intelectuais "donos do poder" (FAORO, 2000) e que se sedimentou institucionalmente enquanto grupo de poder a partir da "cidade letrada" (RAMA, 1984). A solidariedade estabelecida por conjunções coloniais não pode ser pensada fora da segmentação social que o grupo de literatos/burocratas representou nas sociedades coloniais (e pós-coloniais, como veremos quando da discussão sobre Mia Couto). Pretendemos mostrar que a ocupação colonial efetivada por Portugal no Brasil e em parte do continente africano deixou marcas profundas não apenas na criação de estruturas de sentimento racistas como igualmente instituiu uma corte intelectual branca de circulação transnacional. 
No caso do "brasileiro" Tomás Antônio Gonzaga, definido por Antonio Candido (2007, p. 125) como "dos maiores poetas, dentre os sete ou oito que trouxeram alguma coisa à nossa visão de mundo", nascido em Portugal em 1744, e de grande participação não apenas no movimento literário conhecido por Arcadismo (e reconhecido pelo mesmo Antonio Candido como o momento de fundação da literatura brasileira), mas também na revolta em Minas Gerais conhecida por Inconfidência Mineira, interessa-nos particularmente a fase final de sua vida. É importante marcar três momentos da produção intelectual de Gonzaga, filho de pai brasileiro, nordestino, e de mãe portuguesa, de ascendência inglesa. Tendo passado a infância e juventude no Brasil, vai estudar em Portugal e lá compõe um Tratado de Direito Natural, com dedicatória ao Marquês de Pombal. De volta ao Brasil, ocupando o importante cargo de Ouvidor em Vila Rica, região marcada pela exploração mineral sob mão-de-obra africana escravizada, dedica-se à poesia de louvação amorosa, sempre num viés que se apoiava nas conquistas iluministas. Com a prisão dos revoltosos da Conjuração Mineira, e depois de cumprir pena no Brasil, é enviado em 1792 para Moçambique, em degredo. Lá, acaba casado com a herdeira da principal casa de escravatura local. Em Moçambique, adota o tom grandioso, escrevendo o épico $A$ Conceição, poema sobre o naufrágio do navio Marialva (o gênero das tragédias marítimas era comum naquela época). Nunca mais volta ao Brasil ou a Portugal, ocupando importantes postos em Moçambique. O caso de Gonzaga mostra a circulação dos homens de letras sob o escopo colonial português. A casta jurídica portuguesa era necessária à administração da expropriação e do tráfico escravista, seja no Brasil, seja (ainda que a contragosto, pois se tratava de um condenado) na África. Deve-se destacar ser aquele um momento histórico que, no caso brasileiro, opunha diretamente senhores e escravos: "O senhor e o escravo, entretanto, em tudo se separam: no nome, na cor e na fortuna” (FAORO, p. 250). Raymundo Faoro ainda explica que o auge da modernização em Portugal, que se deu sob o Marquês de Pombal, foi também o auge do Pacto Colonial, sistema de expropriação monopolizada das riquezas e do trabalho colonial.

Convocamos agora o percurso biográfico e intelectual do "angolano" Fernando de Castro Soromenho. Nascido em Moçambique, em 1910, filho de pai e mãe portugueses (ela, de família cabo-verdiana), vai cedo para Angola, depois estuda 
em Portugal e acaba voltando adulto para Angola, onde atua inicialmente na Companhia de Diamantes de Angola e, posteriormente, como jornalista, adotando um tom opositor ao colonialismo e à ditadura portuguesa. De volta a Portugal, ainda como jornalista, a partir de 1937, e impedido pelo Estado Novo, do ditador Salazar, de atuar na vida intelectual portuguesa, acaba lançando no Brasil seu romance Terra morta (1949), com viés crítico ao colonialismo. Vem definitivamente para o Brasil em 1965, atuando na Universidade de São Paulo (USP) e falecendo na capital paulista em 1968. O percurso de Soromenho não é muito diferente do de Gonzaga, circulando transnacionalmente por Portugal, Brasil e países africanos. Como Gonzaga, também Soromenho retém certa ambiguidade da casta intelectual do colonialismo. Se o primeiro terminou a vida às voltas com o tráfico de escravos, o segundo operou na extração de diamantes em Angola. Ambos, no entanto, tiveram perfil crítico com relação a Portugal.

Observemos agora alguns pontos de duas produções daqueles intelectuais de circulação colonial. O Tratado de Direito Natural, de Gonzaga, traz uma nítida demarcação hierárquica. Gonzaga faz a distinção de praxe à tratadística do período, distinguindo livre-arbítrio (liberdade) de espontaneidade: “A espontaneidade atribuise aos brutos, que nada obram por vontade, ainda que obrem livres" (GONZAGA, 1942, p. 390). Do mesmo modo, só o livre pode agir. A ação é uma demanda interna, enquanto a paixão é o que se executa sob violência externa. Já em Terra Morta, o romance de Soromenho, vemos uma crítica acentuada ao colonialismo, mas que se dá sob paradigmas literários de matriz portuguesa e, principalmente, da literatura social brasileira surgida na década de 1930 (Jorge Amado, Graciliano Ramos, José Lins do Rego etc.). São obras que dialogam com seus tempos e lugares, mas que sobretudo se afirmam pelo culto da ciência iluminista (Gonzaga) e pela ótica do socialismo científico (Soromenho), ambos de matriz europeia. Tanto em suas obras, como nos seus percursos biográficos, Gonzaga e Soromenho estiveram ambiguamente envolvidos no processo colonial de longa duração. Essa estrutura burocrática e intelectual operada no colonialismo português tinha, pois, circulação transnacional, deixando-nos uma herança de colonialidade ainda bastante persistente. 


\section{De impulsos esparsos a política de Estado: o Brasil e as literaturas africanas}

As primeiras leituras brasileiras de literaturas africanas a deixarem a condição de manifestações episódicas, ocorrem na década de 1970, em particular no âmbito do Centro de Estudos Africanos, da Universidade de São Paulo (USP), mas também em instituições como a Pontifícia Universidade Católica do Rio de Janeiro (PUC-Rio). Surge na USP o periódico multidisciplinar África (CEA/USP), iniciado em 1978 e ainda em vigor, com ênfase nas ciências humanas (Sociologia, História etc.), mas que também publicou um bom número de estudos literários. E na PUC-Rio, ocorre a primeira dissertação brasileira sobre literaturas africanas, defendida por Simone Caputo Gomes, em 1979. Nesse quadro institucional, que também abriga outras iniciativas em Minas Gerais e no Rio Grande do Sul, ocorrem as primeiras investigações sobre literaturas africanas, em geral como extensão institucional dos estudos de literatura portuguesa, mas já sendo marcadamente anticoloniais na sua feição ideológica. A tal impulso acadêmico, corresponde também um primeiro impulso editorial, como o da Coleção Autores Africanos, da Editora Ática. A afirmação daquelas literaturas como "africanas", e particularmente a ênfase na sua condição de literaturas nacionais (de Angola, Moçambique, Guiné-Bissau, Cabo Verde e de São-Tomé e Príncipe), representativas de identidades e histórias autônomas foi um gesto descolonial importante na academia brasileira, operado em geral por impulsos esparsos e sem ordenação institucional. Para que se dimensione a importância do movimento epistemológico de recepção das literaturas africanas, basta lembrar que, na talvez primeira menção que tiveram em livro técnico no Brasil, ainda eram chamadas de literaturas ultramarinas. É o que ocorre na Bibliografia da literatura portuguesa, importante compêndio lançado por Massaud Moisés, em 1968. Ali, a literatura "ultramarina" (algumas antologias e os livros de Castro Soromenho) aparece como uma das nove "épocas" da literatura portuguesa. A própria contradição de critérios temporais de gênero (Classicismo, Barroco etc.) usados para as produções 
portuguesas, e o critério geográfico colonial (Ultramarino) para as produções nãoportuguesas, indica a marcação ideológica do colonialismo.

Passadas quatro décadas daqueles impulsos iniciais, hoje não só o lançamento editorial de literaturas africanas se encontra mais eficiente, com autores de grande circulação, como é o caso de Mia Couto, cuja obra é atualmente editada pela Companhia das Letras, quase uma filial brasileira do grande conglomerado de livros Penguin Random House, maior grupo editorial do mundo, mas também com muitos nomes sendo divulgados em editoras menores, como os autores das editoras Pallas e Kapulana. Assim como a presença editorial, agora não mais limitada apenas aos escritores de língua portuguesa, havendo já alguma circulação de autores africanos não-lusófonos no mercado editorial brasileiro, os estudos sobre literaturas africanas no Brasil constituem uma área muito recente, ainda que já bastante pujante e de marcada institucionalização, com associações de pesquisadores, grupos de pesquisa, congressos, simpósios e difusão de linhas de pesquisas de literaturas africanas nos departamentos de Letras. O país conta atualmente com inúmeros periódicos acadêmicos dedicados, integralmente ou em parte, às literaturas africanas, como, entre outras revistas, a Mulemba (UFRJ), fundada em 2009; a Abril (UFF), de 2008; a Nau Literária (UFRGS), de 2005; a Navegações (PUC-RS), de 2008; a Crioula (USP), de 2007; a Via Atlântica (USP), de 1997. Como se nota, o grande impulso ocorreu no meio da década de 2000, quando são fundadas a maioria das revistas e quando a própria Via Atlântica passa de anual a semestral. Além dessas revistas, inúmeras outras já dedicaram dossiês temáticos às literaturas africanas. É possível dizer, portanto, que já temos um campo de estudos consolidado, o que sugere, no mínimo, a necessidade de um balanço e de um mapeamento mais sistemático da recepção brasileira, de suas categorias, e de sua relação com a questão racial. Isso se dá, fundamentalmente, a partir da criação da Lei 10639/2003, que estabeleceu o estudo e a divulgação da história e da cultura dos afrodescendentes e dos africanos no Brasil, em todos os níveis de ensino. A política afirmativa voltada à educação antirracista surgiu no bojo da criação da Secretaria de Políticas de Promoção da Igualdade Racial (SEPPIR, criada em 2003 e extinta em 2015), com a política de cotas e reconhecimento de áreas quilombolas, além de grande dinamização das relações comerciais, diplomáticas e 
culturais entre o Brasil e os países africanos (VISENTINI et al, 2014). À necessidade de reconhecimento da herança ancestral negra africana junto à população brasileira como um todo e à população afrodescendente em específico, tem correspondido, porém, uma leitura de literaturas africanas ainda impregnadas da marcação racial colonial, isto é, com privilégio das camadas intelectuais coloniais, quase sempre ocupadas por descendentes de portugueses, como é o caso de Mia Couto, mas não somente o dele.

É no contexto dessa política de Estado (através da Lei 10639, modificada em 2008 através da Lei 11645, de modo a incluir também a cultura e a história dos indígenas brasileiros) que ocorre um crescimento significativo nas pesquisas brasileiras sobre literaturas africanas. A partir de levantamento junto ao Catálogo de Teses e Dissertações (plataforma da CAPES), verifica-se que, até 2018, ocorreram mais de mil pesquisas de pós-graduação concluídas nas universidades brasileiras, incluindo-se aí os estudos sobre literaturas de expressão em português e aqueles concernentes às literaturas africanas em francês e inglês. No levantamento foram computadas todas as pesquisas que tivessem nos seus objetos principais (consignados no Resumo ou nas Palavras-chave) nomes de autores (as) da África, sendo contabilizados, portanto, também os trabalhos comparatistas com literatura brasileira, portuguesa ou outras.

Pesquisando apenas as teses e dissertações sobre literaturas africanas de expressão portuguesa defendidas no Brasil entre 1979 e 2018, foram constatados 848 trabalhos, o que mostra a sistematicidade segura atingida pela área acadêmica. É importante destacar, no entanto, que a maioria das pesquisas brasileiras foi realizada bastante recentemente. Mais da metade das dissertações e teses foi defendida no período de 2013 a 2018. Trata-se, recentemente, de um momento de disseminação das investigações em universidades de todo o país e de confirmação acadêmica, na medida em que muitos dos mestres formados no período anterior defenderam agora suas teses de doutorado.

Em levantamento junto ao Catálogo de Teses e Dissertações (disponibilizado pela Coordenação de Aperfeiçoamento de Pessoal de Nível Superior - CAPES) obtivemos um quadro bastante seguro da produção acadêmica brasileira. A partir de 2008, Mia Couto passa a dominar o quadro de pesquisas, tendo, no quadro geral dos 
estudos defendidos até 2018, cerca de $25 \%$ do total de investigações (29\% se computarmos apenas as pesquisas sobre literaturas africanas de expressão portuguesa). O fato põe em questão justamente um dos princípios basilares das pesquisas em literaturas africanas, que é o da descolonização pela diversificação e crítica do cânone ocidental, na medida em que ocorre uma intensa concentração num único escritor. A complicar a onipresença de Mia Couto, ressalte-se a contradição entre a política afirmativa negra presente na Lei 10639 e tal concentração de leituras num autor branco. Há a necessidade, a partir de tal constatação, da revisão dos critérios na escolha de escritores(as) da África, em nome da diversidade cultural/racial e do arejamento do cânone, pondo-se em questão as relações entre as escolhas dos estudos acadêmicos e a monocultura mercadológica e racial de alguns poucos nomes. A questão central é se na área de Letras também ocorre o constatado por Fernando Moreira (2019) quanto à área da Filosofia na Pós-Graduação brasileira. Levantando a presença dos estudos filosóficos da negritude na academia brasileira, Moreira chegou a irrisório número de $0,5 \%$ do total de pesquisas com temática negra: “Tais resultados dão indícios da existência de um racismo acadêmico na filosofia acadêmica brasileira, que age na forma de um silenciamento quase completo quanto a temas negros" (MOREIRA, p. 313). No caso das literaturas africanas, se tomamos para análise os cinco nomes mais estudados na Pós-Graduação brasileira, presentes em quase $70 \%$ das pesquisas brasileiras, apenas a moçambicana Paulina Chiziane é autora negra (os demais são Mia Couto e os angolanos Pepetela, Luandino Vieira e José Eduardo Agualusa).

\section{O fardo branco de Mia Couto}

Para pensarmos no lugar de Mia Couto, escritor de renome mundial e ganhador do prestigiado prêmio Camões, no campo brasileiro de pesquisas sobre literaturas africanas, importa destacar a espécie de monocultura que seus estudos provocaram no vasto rol de autores africanos já discutidos no Brasil. Se muitos dos autores africanos pesquisados no Brasil são verdadeiras pérolas passadas de mão em mão, em virtude de sua ausência no mercado editorial nacional, o caso de Mia Couto é completamente diferente, pois suas obras abundam em disponibilidade e são hoje geridas por um grupo editorial com presença mundial. Tomem-se por exemplo as 
pesquisas comparatistas de triangulação lusófona, aquelas que trazem um autor brasileiro, um português e um da África. Quase sempre o africano utilizado é Mia Couto. Também é um autor "de entrada": muitos pesquisadores fazem o mestrado com Couto e no doutorado ampliam ou modificam o escopo. Essa questão traz ao debate, naturalmente, as relações entre pesquisas acadêmicas e o mercado editorial, que não deve ser pensado em termos exclusivamente nacionais, posto que Mia Couto é hoje um autor de circulação mundial. Um representante da literatura mundial. A esse respeito, acaba de ser lançado um livro coletivo chamado The Worlds of Mia Couto (2020), organizado por Kristian Van Haesendonck.

Antes de tratarmos dessa dimensão, convém pensar quais são as expectativas brasileiras (e portuguesas) reveladas nas pesquisas acadêmicas sobre o autor moçambicano. No caso de Portugal, os estudos costumam pensar a literatura de Couto a partir da inflexão moçambicana/africana da lusocentralidade. Usualmente ressalta-se a condição de uma escrita moçambicana e de uma perspectiva africana que se dá sob a centralidade da língua portuguesa, artifício metodológico que ronda o neocolonialismo. Nesse tipo de abordagem, a língua portuguesa é pensada na sua capacidade de irrigação de diferentes realidades, num processo de mestiçagem e hibridez, numa espécie de continuidade nocional do mundo que "o português criou", isto é, as ditas "constantes portuguesas de caráter e ação" buscadas por Gilberto Freyre (2001) no seu périplo lusotropicalista pelas colônias africanas de Portugal.

Mia Couto é muito estudado com ênfase nos aspectos de invenção linguística de sua literatura. No caso da recepção brasileira, é constante a comparação com o também inventor de linguagem Guimarães Rosa. A ênfase na questão da língua sugere uma "exotização da diferença" — lembrando aqui da noção de "exótico póscolonial”, de Graham Huggan (2001), autor que apontou uma ambiguidade entre o potencial crítico das literaturas pós-coloniais e a diminuição desse potencial na mercantilização mundial daquelas literaturas. Para Brugioni (2019), a língua literária de Mia Couto seria uma "língua alheia" à norma do português de Portugal e de Moçambique também, agindo preponderantemente como "tradução". No caso da recepção, principalmente na europeia, haveria tal obsessão linguística, com uma imensidão de trabalhos que analisam a questão linguística do autor, em busca de associação entre língua literária e o português europeu ou moçambicano. Não haveria, 
pois, leituras que ressaltassem a condição política dessa língua literária, havendo mais a valorização das potencialidades linguísticas do português europeu.

Sabemos que tampouco é pacífico o lugar de Couto no campo literário moçambicano. A discussão já é antiga e data da publicação de Voz̧es anoitecidas (2013), livro de contos lançado em Moçambique, em 1984. Fátima Mendonça, no artigo "Mia Couto, le mal-aimé" (2008) destaca a ambiguidade das discussões moçambicanas e portuguesas quanto ao romance Terra Sonâmbula, lançado em Moçambique em 1992. Se a recepção moçambicana a Mia Couto foi marcada, já no seu início, como escritor de ficção, pela discussão entre ser ou não autêntico, a recepção portuguesa ressaltou a condição de retrato de nação e cultura na obra do autor. Assim, na recepção portuguesa (e poderíamos pensar também em grande parte nas leituras brasileiras) para Terra Sonâmbula, tudo o que seria contestado no plano interno estava sendo valorizado externamente: haveria homologia entre experiência linguística e realidade social, o exotismo linguístico seria valorizado como experiência literária, a literatura de Mia faria correta apropriação cultural. Em geral, muitas leituras externas tomaram o romance como um manual antropológico, ignorando em absoluto a história moçambicana, contesta Fátima Mendonça.

No caso do Brasil, a recepção a Mia Couto é usualmente pensada numa espécie de culturalismo que tende a ressaltar o retrato de uma suposta moçambicanidade, a transcrição literária de padrões de oralidade ancestrais em Moçambique, o lúdico da criação verbal que o aproximaria de Guimarães Rosa (perspectiva que reforça uma noção de comunidade sem arestas entre Brasil e Moçambique). Principalmente, destaca-se a leitura de uma suposta multiculturalidade absoluta no país africano, presente nas obras de Couto, ressaltando uma condição híbrida. A esse respeito, o hibridismo seria também condição necessária à circulação mundial de nomes como Mia Couto ou do angolano Agualusa. Nesse sentido, Nazir Can destaca, em O campo literário moçambicano (2020, p. 113), que "a poética que aposta na combinação de formas e culturas ("híbridas") parece adequar-se mais ao horizonte de expectativa editorial e acadêmica, tanto no Brasil como em Portugal, receptores primeiros da literatura moçambicana". 
Além disso, a profusão de estudos sobre o autor não necessariamente traz ganhos epistemológicos. É o que aponta Ana Claudia Silva (2010, p. 77), destacando uma repetição de temas e métodos nas pesquisas brasileiras sobre Mia Couto, constatando que "tais investigações, refeitas em vários trabalhos, fizeram-nos supor que os pesquisadores brasileiros da obra de Mia Couto não liam os trabalhos uns dos outros".

Partindo de tantos pressupostos, temos a questão: onde ficam, nas recepções acadêmicas brasileira e portuguesa tão interessadas na semelhança (seja com a construção linguística de Guimarães Rosa, seja na perspectiva neolusotropicalista do elogio da hibridez e da mestiçagem, o "moçambicano" e o “africano” em Mia Couto? Isto é, onde ficam as diferenças e a condição sempre aberta da literatura? De um lado, certamente deveríamos abordar sua obra mais nos seus aspectos literários. Elena Brugioni sugere, a respeito, uma atenção à condição de tradução presente na linguagem literária do autor. De outro lado, interpretações que situem Mia Couto sob a moldura das dinâmicas atuais do capitalismo mundial fazem falta. De certo modo, poderia estar aí um antídoto contra o culturalismo que vê na obra do autor um manual de etnografia moçambicana. A exotização, nesse ponto, é a da condenação ao passado do contexto africano no qual emergem os textos de Couto, o que nos sugere a crítica ao culturalismo como forma de mundanizar de modo materialista e racial a discussão das literaturas africanas.

No ensaio de 1996, "Quando foi o pós-colonial? Pensando no limite”, Stuart Hall (2003) discutiu as diversas críticas que a categoria pós-colonial havia recebido até então. Hall rebate as críticas, mas aceita que há uma lacuna na ausência de interpretações que também pensem os novos desenvolvimentos do capitalismo global e sua relação com as literaturas pós-coloniais. Para romper a imagem de "culturalismo" nas leituras brasileiras de Mia Couto, com as respectivas abstrações universalizantes de hibridismo e identidade, imagem que tem consequências indiretas na predileção pelas relações (de passagem) entre oralidade e literatura, não muito distante do fetiche da memória ancestral e da imaginação de nação, para romper tal culturalismo, a consideração das literaturas pós-coloniais demandaria entrelaçamentos com leituras do mundo capitalista e com as dinâmicas raciais brasileiras e transnacionais. Uma das tensões imediatas em tal relação é o próprio estatuto de 
mercadoria (institucional, mas não apenas) do pós-colonial. Para além disso, a própria condição de mercadoria da literatura africana junto ao mercado mundial (ocidental, melhor dizendo) e, talvez até mais, nos fetiches do autor e da autora africana. É sempre útil lembrar que são brancos os dois autores mais pesquisados nas literaturas africanas lusófona e não-lusófona (Mia Couto e o sul-africano J. M. Coetzee). E são negras as duas autoras mais pesquisadas nas lusófonas e nas não-lusófonas (Paulina Chiziane e a nigeriana diaspórica Chimamanda Adichie).

Nesse ponto, a recepção brasileira a Mia Couto não pode deixar de considerar a questão racial tal qual está estruturada nas nossas instituições, como nas universidades e em suas pesquisas. O que não significa dizer, ressalte-se, que a simples leitura de Mia Couto reitere padrões de branquitude brasileiros. Até porque, ideologicamente a literatura de Mia Couto tenta escapar desse dilema ao sugerir um tempo pós-racial. Jefferson Tenório (2013), ao discutir a questão em Mia Couto, aponta para essa postura no autor, de uma africanidade sincrética. De outro lado, é preciso ressaltar o quanto há de liberal nessa fórmula que situa no indivíduo e na vontade determinadas constrições que são estruturais (como o racismo colonial, no caso). Isso está presente em Mia Couto e, nesse ponto, entender a dimensão mundana de sua literatura passaria também por investigações do lugar social/ideológico/racial de suas obras. No ensaio "E se Obama fosse africano?”, por exemplo, Couto destaca um problema de "atitude" nos moçambicanos e africanos em geral, que ficariam eternamente no vitimismo da herança colonial. Ao comemorarem a vitória eleitoral de Obama, as lideranças africanas estariam sendo hipócritas, pois também seriam racistas e contra os direitos humanos, além de corruptos. É o caso de perguntarmos: se Mia Couto não fosse africano branco, herdeiro de padrões de colonialidade ambíguos (e sistêmicos, como sugerimos ao traçar os percursos de Tomás Antônio Gonzaga e de Castro Soromenho), ele teria a circulação que tem hoje no Brasil, um país que em 2003 criou uma legislação afirmativa que em muito nos aproximou das literaturas africanas? Fica aqui um tema complexo e repleto de contradições para futuras discussões. 


\section{Considerações finais}

A partir de tais pressupostos, não parece difícil entender da necessidade de outra mediação na dinâmica das relações entre as leituras brasileiras e as literaturas africanas, pois a recepção brasileira usualmente faz uso da ideia de lusofonia enquanto comunidade, prevendo sintonias às vezes forçadas entre as obras literárias africanas e as brasileiras, como no caso das associações entre Mia Couto e Guimarães Rosa. Igualmente, pressupõe uma sociedade sincrética e híbrida em Moçambique, numa reiteração de padrões culturais lusotropicalistas. Assim, pensar na especificidade da apreensão crítica brasileira das obras moçambicanas nos convida a repensar todos os conceitos mais generalizantes, como "alteridade" ou "diferença", impondo-lhes a prova do condicionamento histórico e mundial e demandando a intersecção da questão racial nos seus componentes históricos e políticos, como é o caso da escravização, do racismo estrutural brasileiro e das políticas afirmativas e das práticas de descolonização universitária mais recentes. Às voltas com um mercado monopolista (como no exemplo de Mia Couto como o "único" moçambicano reconhecido pelos cifrões), as políticas públicas de educação, escoradas na ascensão das políticas afirmativas em nome da diversidade e do fim da desigualdade e do preconceito racial, buscaram recentemente estimular o consumo e a vivência cidadã da diversidade através da propagação das literaturas afro-brasileira e africana. Instituiu-se, porém, um outro imperialismo entre países como Brasil e Portugal em relação aos países africanos, sendo estes o polo de dependência da recepção comercial e crítica das suas produções culturais. Entender a presença das literaturas africanas no Brasil, e sob que categorias sua apreensão é feita, é essencial para repensar a literatura a partir de cortes localizados e transversais, encetando outras cartografias e geopolíticas culturais e raciais. Evocando o fato de que as literaturas africanas se esmeram na explicitação crítica de que não há estabilidade nas representações identitárias, pensar em tais literaturas é necessariamente um esforço dialógico em relação, por exemplo, à sua percepção fora da África. Literaturas africanas, nesse sentido, seriam um termo relacional, a serem pensadas também no escopo de sua recepção externa. No caso brasileiro, uma recepção estruturalmente marcada pela persistência das contradições e das violências da questão racial. 


\section{Referências}

ABDALA JUNIOR, B. "Necessidade e solidariedade nos estudos de literatura comparada". Revista Brasileira de Literatura Comparada, v. 3, n. 3, 1996.

ABDALA JUNIOR, B. "Notas históricas: solidariedade e relações comunitárias nas literaturas dos países africanos de língua portuguesa”. Niterói, n. 24, p. 31-44, 2008.

BRASIL. Lei 10.639/2003, de 9 de janeiro de 2003. Altera a Lei nº 9. 394, de 20 de dezembro de 1996. Diário Oficial da União, Poder Executivo, Brasília.

BRASIL. Lei 11.645/08, de 10 de Março de 2008. Diário Oficial da União, Poder Executivo, Brasília.

BRUGIONI, E. Literaturas africanas comparadas: paradigmas críticos e representações em contraponto. Campinas: Editora da Unicamp, 2019.

CAN, Nazir. O campo literário moçambicano. Tradução do espaço e formas de insílio. São Paulo: Editora Kapulana, 2020.

CANDIDO, A. Formação da literatura brasileira: momentos decisivos. Rio de Janeiro: Ouro sobre Azul, 2007.

COUTO, M. E se Obama fosse africano? E outras interinvenções. São Paulo: Companhia das Letras, 2011.

COUTO, M. Vozes Anoitecidas. São Paulo: Companhia das Letras, 2013.

FAORO, R. Os donos do poder: formação do patronato político brasileiro. São Paulo:

Globo; Publifolha, 2000.

FREYRE, G. Aventura e rotina. Sugestões de uma viagem à procura das constantes portuguesas de caráter e ação. Rio de Janeiro: Topbooks, 2001.

GOMES, S. C. Uma recuperação de raiz: Cabo Verde na obra de Daniel Filipe. Dissertação (Mestrado em Letras) - Pontifícia Universidade Católica do Rio de Janeiro, 1979.

GONZAGA, T. A. Obras completas de Tomás Antônio Gonzaga. São Paulo: Companhia Editora Nacional, 1942. (Edição crítica de Rodrigues Lapa).

HAESENDONCK, K. The Worlds of Mia Couto. Oxford: Peter Lang Limited International Academic Publishers, 2020. 
HALL, S. Da diáspora: Identidades e mediações culturais. Belo Horizonte: Editora UFMG; Brasília: Representação da UNESCO no Brasil, 2003.

HUGGAN, G. The postcolonial exotic. Marketing the margins. London; New York: Routledge, 2001.

MARX, K. O Capital. São Paulo: Abril Cultural, 1985.

MENDONÇA, F. "Mia Couto, le mal-aimé”. Études littéraires africaines, n. 25, p. 41-48, 2008.

MOISÉS, M. Bibliografia da literatura portuguesa. São Paulo: Edição Saraiva, Editora da Universidade de São Paulo, 1968.

MOREIRA, F. S. Estudos filosóficos sobre o negro no Brasil: um levantamento de teses e dissertações em temáticas negras nos programas de pós-graduação da área de filosofia (1987-2018). Problemata: R. Intern. Fil., v. 10, n. 2, p. 313-34, 2019.

RAMA, A. La ciudad letrada. Montevideo: Fiar, 1984.

SILVA, A. C. O rio e a casa: imagens do tempo na ficção de Mia Couto [online]. São Paulo: Editora UNESP; São Paulo: Cultura Acadêmica, 2010.

SOROMENHO, C. Terra morta. Rio Tinto (Portugal): União dos Escritores Angolanos, 1988.

TENÓRIO, J. S. Quando é ser africano? Em busca do Outro pé e outros niilismos na obra de Mia Couto. 85f. Orientador: TETTAMANZY, L. L. Dissertação (Mestrado em Letras) — Universidade Federal do Rio Grande do Sul, 2013.

VISENTINI, P. F. História da Africa e dos africanos. Petrópolis: Vozes, 2014. 